\title{
White Light Generation with CdSe/ZnS Core-Shell Nanocrystals and InGaN/GaN Light Emitting Diodes
}

\author{
Sedat Nizamoglu ${ }^{\dagger \ddagger}$, Tuncay Ozel ${ }^{\dagger \ddagger}$, Emre Sari ${ }^{* \ddagger}$, and Hilmi Volkan Demir* ${ }^{\dagger *}$ \\ ${ }^{\dagger}$ Department of Physics, *Department of Electrical and Electronics Engineering, and ${ }^{\ddagger}$ Nanotechnology Research Center \\ Bilkent University, Ankara, Turkey TR-06800 \\ Email: volkan@bilkent.edu.tr, Telephone: [+90] (312) 290-1021, Fax: [+90] (312) 290-1015
}

\begin{abstract}
We present hybrid white light sources that integrate CdSe/ZnS core-shell nanocrystals on blue InGaN/GaN light emitting diodes (LED). We report on the demonstrations of white light generation using yellow nanocrystals $\left(\lambda_{\mathrm{PL}}=580 \mathrm{~nm}\right)$ hybridized on a blue LED $\left(\lambda_{\mathrm{EL}}=440 \mathrm{~nm}\right)$ with tristimulus coordinates of $x=0.37$ and $y=0.25$, correlated color temperature of $T_{c}=2692 \mathrm{~K}$, and color rendering index of $R_{a}=14.6$; cyan and red nanocrystals $\left(\lambda_{\mathrm{PL}}=500 \mathrm{~nm}\right.$ and $\left.620 \mathrm{~nm}\right)$ on a blue LED $\left(\lambda_{\mathrm{EL}}=440 \mathrm{~nm}\right)$ with $x=0.37, y=0.28, T_{\mathrm{c}}=3246 \mathrm{~K}$, and $R_{\mathrm{a}}=19.6$; and green, yellow, and red nanocrystals $\left(\lambda_{\mathrm{PL}}=540 \mathrm{~nm}, 580 \mathrm{~nm}\right.$, and $620 \mathrm{~nm})$ on a blue LED $\left(\hat{\lambda}_{E L}=452 \mathrm{~nm}\right)$ with $x=0.30, y=0.28$, $T_{c}=7521 \mathrm{~K}$, and $R_{\mathrm{a}}=40.9$.
\end{abstract}

Keywords- CaSe/ZnS, core-shell, nanocrystal; blue, InGaN/GaN, LED; nano-hybrid device; white light.

\section{INTRODUCTION}

In recent decades, a tremendous improvement in GaN-based LEDs has been achieved and GaN-based LEDs have been commercialized. ${ }^{1}$ These LEDs have found a wide range of applications in traffic lights, full color displays, optical storage and lighting. Specifically white light LEDs have attracted a great deal of scientific and commercial interest due to their wide scale use in solid-state lighting and liquid-crystal display (LCD) backlighting. ${ }^{2}$ For white light generation, different approaches have been exploited: multi-chip white-LEDs, monolithic white-LEDs and color-conversion white LEDs (e.g., with phosphorus). ${ }^{3}$ Recently, white light generation has been achieved using a nano-hybrid device approach that relies on the use of nanocrystals and LEDs in our research group (Fig. 1) and the others. ${ }^{4-6}$



Figure 1: Photograph of white light generation with our LEDs coated with nanocrystals.

In this work, we present different single, dual and trio combinations of $\mathrm{CdSe} / \mathrm{ZnS}$ core-shell nanocrystals coated on blue InGaN/GaN LEDs for white light generation. Sample 1 consists of yellow nanocrystals $\left(\lambda_{\mathrm{PL}}=580 \mathrm{~nm}\right)$ hybridized on a blue LED $\left(\lambda_{\mathrm{EL}}=440 \mathrm{~nm}\right)$ and exhibits tristimulus coordinates of $\mathrm{x}=0.37$ and $\mathrm{y}=0.25$, correlated color temperature of $\mathrm{T}_{\mathrm{c}}=2692 \mathrm{~K}$, and color rendering index of $\mathrm{R}_{\mathrm{a}}=14.6$. Sample 2 contains cyan and red nanocrystals $\left(\lambda_{\mathrm{PL}}=500 \mathrm{~nm}\right.$ and $\left.620 \mathrm{~nm}\right)$ integrated on a blue LED $\left(\lambda_{\mathrm{EL}}=440 \mathrm{~nm}\right)$ and features $\mathrm{x}=0.37$, $y=0.28, T_{c}=3246 \mathrm{~K}$, and $R_{a}=19.6$. Sample 3 is composed of green, yellow, and red nanocrystals $\left(\lambda_{\mathrm{PL}}=540 \mathrm{~nm}, 580 \mathrm{~nm}\right.$, and $620 \mathrm{~nm})$ coated on a blue LED $\left(\lambda_{E L}=452 \mathrm{~nm}\right)$ and achieves $\mathrm{x}=0.30, \mathrm{y}=0.28, \mathrm{~T}_{\mathrm{c}}=7521 \mathrm{~K}$, and $\mathrm{R}_{\mathrm{a}}=40.9$.

\section{CHARACTERIZATION AND RESULTS}

\section{A. Characterization of LEDs and nanocrystals}

After we grow our LED epitaxial wafers on sapphire using MOCVD at Bilkent Nanotechnology Research Center, we use standard lithography, mesa reactive ion etching and metalization steps to fabricate our LEDs. The electroluminescence characteristics of the fabricated LEDs are shown in Fig. 2.

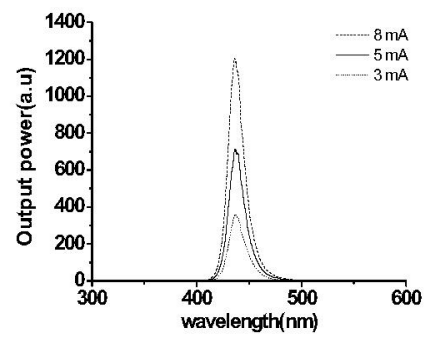

(a)

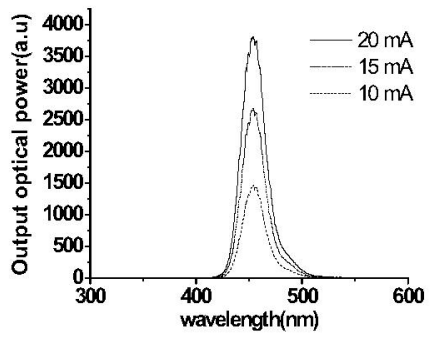

(b)

Figure 2: Electroluminescence spectra of our LEDs at various current injection levels with the peak emission wavelengths of (a) $440 \mathrm{~nm}$ and (b) $452 \mathrm{~nm}$. 
To functionalize the LED top surface, we hybrid-integrate our LEDs with our CdSe/ZnS core-shell nanocrystals via surface treatment, spin-casting and curing. The photoluminescence characteristics of our nanocrystals are shown in Fig. 3.

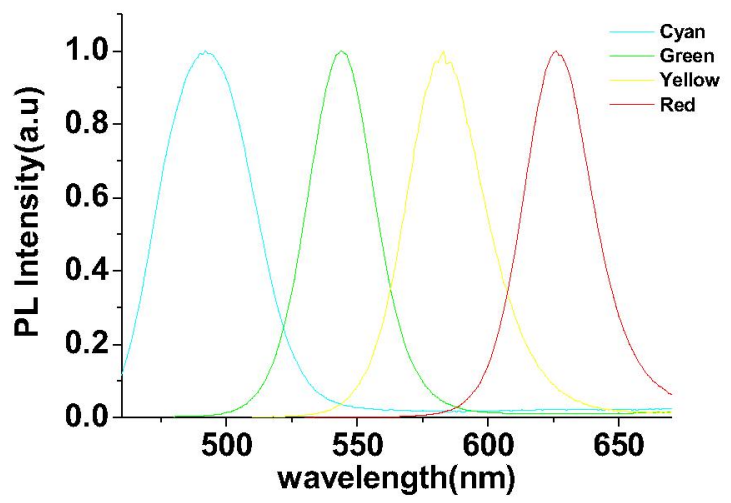

Figure 3. Photoluminescence characteristics of our cyan, green, yellow, and red $\mathrm{CdSe} / \mathrm{ZnS}$ core-shell nanocrystals.

\section{B. Characterization of white hybrid nanocrystal LEDs}

In operation, the LED that is electrically driven optically pumps the integrated nanocrystal films and, consequently, the nanocrystal photoluminescence and the LED electroluminescence contribute together to the white light generation. To satisfy the white light condition on C.I.E. chromaticity diagram, the relative optical power of the emitted light at the chosen wavelengths can be tuned using the hybrid device parameters including the type and density of nanocrystals and the thickness and order of the nanocrystal films.

The relative optical emission spectra of Sample 1 that consists of yellow nanocrystals $\left(\lambda_{\mathrm{PL}}=580 \mathrm{~nm}\right)$ hybridized on a blue LED $\left(\lambda_{\mathrm{FL}}=440 \mathrm{~nm}\right)$ are shown at various current injection levels in Fig. 4. These spectra correspond to the tristimulus coordinates of $\mathrm{x}=0.37$ and $\mathrm{y}=0.25$ on C.I.E. (1931) chromaticity diagram, the correlated color temperature of $T_{c}=2692 \mathrm{~K}$, and the color rendering index of $R_{a}=14.6$. This falls in the white region in chromaticity diagram as shown in Fig. 7. However, the color rendering index is low due to the dichromatic characteristics of this white hybrid LED.

For Sample 2, we integrate dual cyan and red nanocrystals $\left(\lambda_{\mathrm{PL}}=500 \mathrm{~nm}\right.$ and $\left.620 \mathrm{~nm}\right)$ on a blue LED $\left(\lambda_{\mathrm{EL}}=440 \mathrm{~nm}\right)$. The relative optical emission spectra of Sample 2 are shown at various current injection levels in Fig. 5. These spectra correspond to $\mathrm{x}=0.37, \mathrm{y}=0.28, \mathrm{~T}_{\mathrm{c}}=3246 \mathrm{~K}$, and $\mathrm{R}_{\mathrm{a}}=19.6$, which is also in the white region as shown in Fig. 7. In this case, the color rendering index is improved with respect to the dichromatic source of Sample 2.

For Sample 3, we us a combination of green, yellow, and red nanocrystals $\left(\lambda_{\mathrm{PL}}=540 \mathrm{~nm}, 580 \mathrm{~nm}\right.$, and $\left.620 \mathrm{~nm}\right)$ integrated on a blue LED $\left(\lambda_{\mathrm{EL}}=452 \mathrm{~nm}\right)$. The emission spectra of Sample 3 are shown at various current injection levels in Fig. 6. These spectra correspond to $\mathrm{x}=0.30, \mathrm{y}=0.28, \mathrm{~T}_{\mathrm{c}}=7521 \mathrm{~K}$, and $\mathrm{R}_{\mathrm{a}}=40.9$. This operating point mathematically falls into the white region in chromaticity diagram as shown in Fig. 7. Because of trichromaticity of this hybrid LED, the color rendering index is the highest in this case, compared to Samples 1 and 2 .

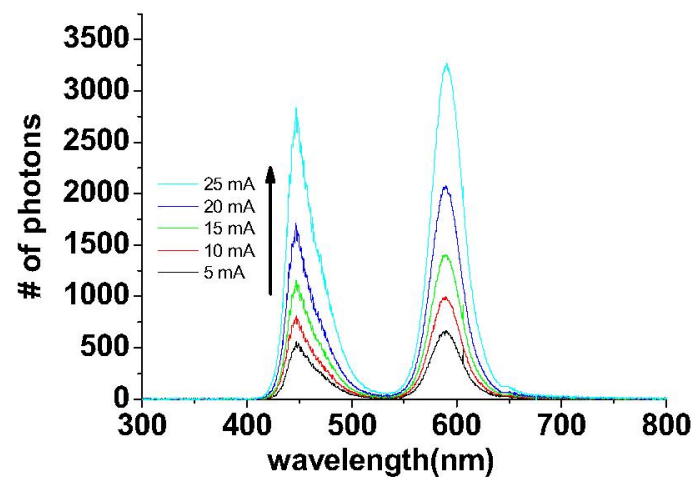

Figure 4. Emission spectra of yellow nanocrystals $\left(\lambda_{\mathrm{PL}}=580\right.$ $\mathrm{nm})$ hybridized with blue LED $\left(\lambda_{\mathrm{EL}}=440 \mathrm{~nm}\right)$ at various current injection levels (Sample 1).

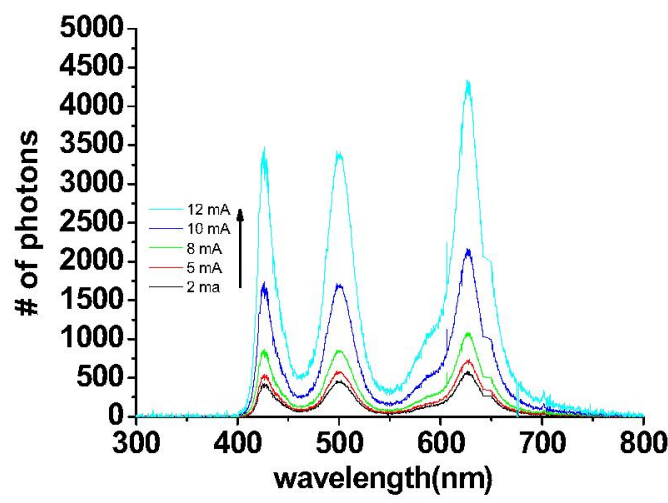

Figure 5. Emission spectra of dual cyan and red nanocrystals $\left(\lambda_{\mathrm{PL}}=500 \mathrm{~nm}\right.$ and $\left.620 \mathrm{~nm}\right)$ hybridized with blue LED $\left(\lambda_{\mathrm{EL}}=440\right.$ $\mathrm{nm}$ ) at various current injection levels (Sample 2).

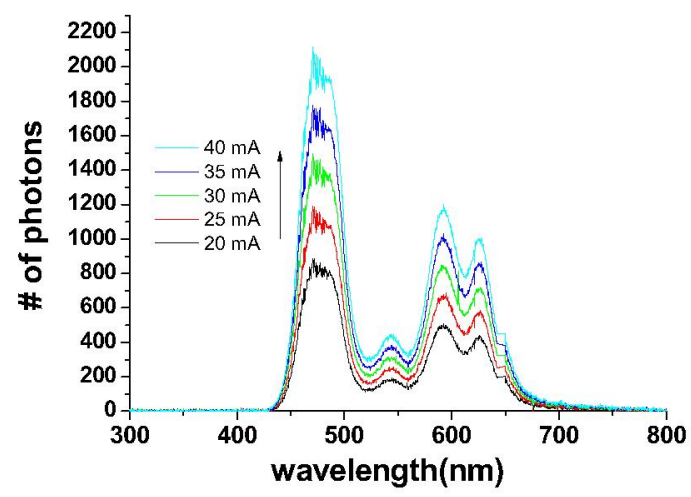

Figure 6. Emission spectra of green, yellow, and red nanocrystals $\left(\lambda_{\mathrm{PL}}=540 \mathrm{~nm}, 580 \mathrm{~nm}\right.$, and $\left.620 \mathrm{~nm}\right)$ hybridized on blue LED ( $\left.\lambda_{\mathrm{EL}}=452 \mathrm{~nm}\right)$ at various current injection levels.

Figure 3 shows the operating points of Samples 1, 2, and 3 on C.I.E. (1931) chromaticity diagram ${ }^{3}$. All of these samples accomplish white light generation. 


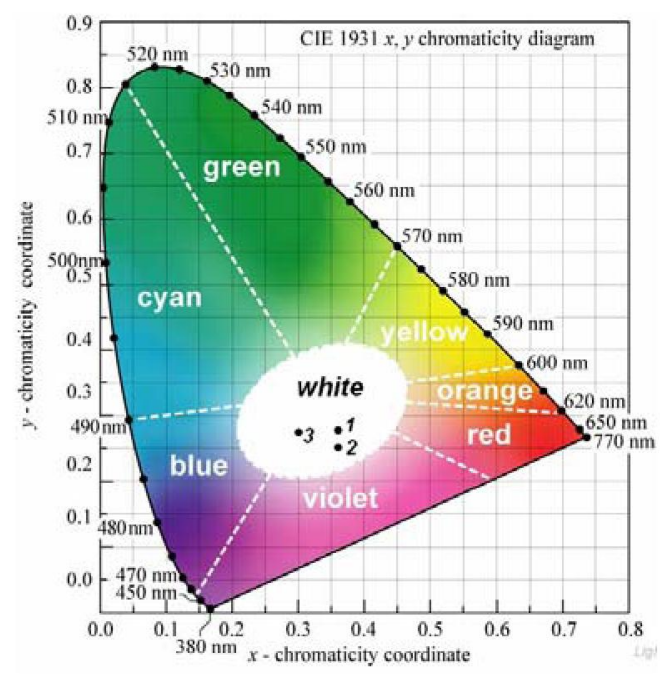

Figure 7. Samples 1, 2, and 3 in white region on C.I.E. (1931) chromaticity diagram ${ }^{3}$.

\section{III.CONCLUSION}

In this paper we present hybrid white light sources that integrate $\mathrm{CdSe} / \mathrm{ZnS}$ core-shell nanocrystal films on blue InGaN/GaN LEDs. These hybrid white light sources hold promise for future lighting and display applications.

\section{ACKNOWLEDGMENT}

This work is supported by a Marie Curie European Reintegration Grant MOON 021391 and EUPHOREMOST Network of Excellence 511616 within the $6^{\text {th }}$ European Community Framework Program and TUBITAK under the Project Nos. 104E114, 106E020, 105E065, and 105E066. H.V.D. and S.N. also acknowledge additional support from Turkish Academy of Sciences and TUBITAK.

\section{REFERENCES}

[1] S. Nakamura and G. Fasol, The Blue Laser Diode (Springer, Berlin, 1997).

[2] M. Arik, J. Petroskf, S. Weavery, "Thermal Challenges in the Future Generation Solid State Lighting Applications: Light Emitting Diodes," Inter Society Conference on Thermal Phenomena, pp. 112-120, (2002).

[3] E. F. Schubert, Light-Emitting Diodes, (Cambridge University Press, 2006).

[4] H. Chen, D. Yeh, C. Lu, C. Huang, W. Shiao, J. Huang, C. C. Yang, I. Liu, and W. Su, "White Light Generation With CdSe-ZnS NanocrystalsCoated on an InGaN-GaN QuantumWell Blue/Green Two-Wavelength Light-Emitting Diode", IEEE Photon. Technol. Lett., vol. 18, no. 13, pp 1430-1432, (2006).

[5] H. Chen, C. Hsu, and H. Hong, "InGaN-CdSe-ZnS Quantum Dots White LEDs", IEEE Photon. Technol. Lett., vol. 18,no. 1, pp. 193-195, (2006)

[6] M. A. Petruska, D. D. Koleske,M. H. Crawford, and V. I. Klimov, "Nanocrystal-Based Light-Emitting Diodes Utilizing High-Efficiency Nonradiative Energy Transfer for Color Conversion", Nanoletters, vol. 6, no. 7, pp. 1396-1400, (2006). 